\title{
Core-shell-shell cytocompatible polymer dot-based particles with near-infrared emission and enhanced dispersion stability
}

DOI:

$10.1039 / \mathrm{c} 8 \mathrm{cc} 04310 \mathrm{~h}$

\section{Document Version}

Accepted author manuscript

Link to publication record in Manchester Research Explorer

Citation for published version (APA):

Shanks, H., Zhu, M., Milani, A., Turton, J., Haigh, S., Hodson, N., Adlam, D., Hoyland, J., Freemont, T., \& Saunders, B. (2018). Core-shell-shell cytocompatible polymer dot-based particles with near-infrared emission and enhanced dispersion stability. Chemical Communications, 54, 9364-9367. https://doi.org/10.1039/c8cc04310h

\section{Published in:}

Chemical Communications

\section{Citing this paper}

Please note that where the full-text provided on Manchester Research Explorer is the Author Accepted Manuscript or Proof version this may differ from the final Published version. If citing, it is advised that you check and use the publisher's definitive version.

\section{General rights}

Copyright and moral rights for the publications made accessible in the Research Explorer are retained by the authors and/or other copyright owners and it is a condition of accessing publications that users recognise and abide by the legal requirements associated with these rights.

\section{Takedown policy}

If you believe that this document breaches copyright please refer to the University of Manchester's Takedown Procedures [http://man.ac.uk/04Y6Bo] or contact uml.scholarlycommunications@manchester.ac.uk providing relevant details, so we can investigate your claim.

\section{OPEN ACCESS}




\section{Journal Name}

\section{COMMUNICATION}

\section{Core-shell-shell cytocompatible polymer dot-based particles with near-infrared emission and enhanced dispersion stability}

Received 00th January 20xx Accepted 00th January 20xx

DOI: $10.1039 / x 0 x \times 00000 x$
Hannah R. Shanks ${ }^{\mathrm{a}}$, Mingning Zhu ${ }^{\mathrm{a}}$, Amir H. Milani ${ }^{\mathrm{a}}$, James Turton ${ }^{\mathrm{a}}$, Sarah Haigh ${ }^{\mathrm{a}}$, Nigel W. Hodson $^{\mathrm{b}}$, Daman Adlam ${ }^{\mathrm{c}}$, Judith Hoyland ${ }^{\mathrm{c}, \mathrm{d}}$, Tony Freemont ${ }^{\mathrm{c}, \mathrm{d}}$ and Brian R. Saunders ${ }^{\mathrm{a}, *}$

www.rsc.org/

Polymer dots (PDs) are promising fluorescent probes for biomaterials applications. Here, novel cytocompatible composite PD particles have been synthesised with a core-shell-shell morphology. The particles show near-infrared emission, improved fluorescent brightness and enhanced colloidal stability compared to pure PDs. The particles also show non-radiative resonance energy transfer (NRET) with a model dye.

Polymer dots (PDs) are nanometre-sized particles prepared from semiconducting polymers ${ }^{1}$. Their band gaps are controlled by the structure of the parent conjugated polymer which enables tuneable visible light absorption and fluorescence emission ${ }^{2-4}$. PDs are normally prepared using nanoprecipitation which is a convenient method that involves the rapid precipitation of the conjugated polymer and stabilisation of the nanoparticles using a surfactant ${ }^{5,6}$. PDs display excellent photostability, making them promising materials for fluorescent labels, for uses such as in vivo cellular imaging, or tumour targeting ${ }^{4,12}$ as well as biosensors and LEDs $^{4,7,8,13}$. PDs are attractive for biomaterials applications because they have reduced cytotoxicity compared to inorganic quantum dots ${ }^{4}$. Of particular interest is including near-infrared (NIR) dyes into the PDs to enable NIR imaging ${ }^{9,10}$, which is deeply penetrating in human tissue ${ }^{14}$. Unfortunately, nanoprecipitation though well-established, limits the morphologies available to a simple PD core with a stabilising shell. This method can also make it difficult to vary the location of the conjugated polymer within composite particles, which

\footnotetext{
School of Materials, University of Manchester, MSS Tower, Manchester, M13 9PL, U.K.

BioAFM Facility, Faculty of Biology, Medicine and Health, Stopford Building, University of Manchester, Oxford Road, Manchester, M13 9PT, UK.

Division of Cell Matrix Biology and Regenerative Medicine, Faculty of Biology, Medicine and Health, University of Manchester, Oxford Road, Manchester, M13 SPT, U.K.

d. NIHR Manchester Musculoskeletal Biomedical Research Centre, Central Manchester Foundation Trust,, Manchester Academic Health Science Centre, Manchester, UK

† Footnotes relating to the title and/or authors should appear here.

Electronic Supplementary Information (ESI) available: [Experimental details and additional data]. See DOI: 10.1039/x0xx00000x
}

reduces particle morphology options. Here, we report a unique core-shell-shell (CSS) PD morphology for the first time.

PDs for in vivo imaging should ideally have a high fluorescence quantum yield ( $Q Y$ ), narrow NIR emission, be biocompatible, and have good colloidal stability. PDs have QYs that are much less than $100 \%$ due, in large part, to emission self-quenching ${ }^{15,16}$. Colloidal stability can also be limited if this relies on physically adsorbed stabilisers. Relatively few NIR PD dispersions show both good colloidal stability and high PD quantum yields ${ }^{17,}{ }^{18}$. To improve colloid stability of such systems block copolymer stabilisers have recently been used ${ }^{9}$. In this study we establish novel CSS NIR particles which have improved brightness and colloidal stability compared to the parent PDs. Furthermore, they show non-radiative resonance energy transfer (NRET) in the presence of a model dye.

The original aim of our programme was to prepare coreshell dispersions where PDs formed the core. The water soluble polymer surfactant poly(styrene-co-maleic anhydride) (PSMA) (see Scheme S1, ESI ${ }^{+}$) ring opens in water to form an amphiphilic $-\mathrm{COO}^{-}$ich copolymer ${ }^{8}$. We hypothesised that the hydrophobicity of PSMA and, hence, the surface of PD stabilised by PSMA in water would increase if the $\mathrm{pH}$ of the dispersion was decreased to below the PSMA $\mathrm{p} K_{a}$. It was further posited that under such $\mathrm{pH}$ conditions the PDs would act as seeds for heterogeneous growth of core-shell particles via emulsion polymerisation, if suitable acrylic monomers and free-radicals were present. However, to our surprise a multishell PD-based morphology was produced. We term these particles as CSS composite PD particles. (Scheme S1, ESIt) Whilst CSS particles have been studied ${ }^{19}$, the inclusion of conjugated polymers into such particles is new.

As described in the Experimental Section (ESI+) PDs were prepared by nanoprecipitation using a modification to an earlier method ${ }^{20}$. We used PSMA as a $\mathrm{pH}$-responsive stabiliser. The semiconducting polymer was poly[2-methoxy-5-(2ethylhexyloxy)-1,4-phenylenevinylene (MEH-PPV) and the NIR dye was silicon 2,3-naphthalocyanine bis(trihexylsilyloxide) (NIR775). MEH-PPV, NIR775 and PSMA were dissolved in THF. This solution was rapidly added to water with sonication which 
triggered PD formation. The THF was then removed by rotary evaporation, resulting in an NIR PD dispersion (see Scheme S1, $\mathrm{ESI}+$ ). In order to grow a copolymer onto the surface of the seed PD particles via emulsion polymerisation, it was considered essential that the seed particles were adjusted to become relatively hydrophobic ${ }^{21}$. Accordingly, the PD dispersion $\mathrm{pH}$ was decreased to 3.8 , which partially destabilised the dispersion causing limited PD aggregation. A comonomer feed together with ammonium persulfate (APS) was added and the mixture heated to $80{ }^{\circ} \mathrm{C}$. The comonomers used were ethyl acrylate (EA), methacrylic acid (MAA) and butanediol diacrylate (BDDA), with feed mass ratios of 79:20:1 respectively. The PD aggregates acted as seeds for PEA-MAABDDA shell growth under starved feed emulsion polymerisation conditions. As will be shown additional PDs also adsorbed to the PEA-MAA-BDDA shell to give CSS composite particles (see Scheme 1, ESI + ).

The PDs were prepared at $\mathrm{pH} 5.5$ and were mostly well dispersed and had a diameter of $3.0 \mathrm{~nm}$ as judged by TEM (see Fig. S1a, ESI + ). There were also occasional larger aggregates of loosely bound PDs present which dominated dynamic light scattering (DLS) measurements (see Fig. S3a, ESIt). (Control experiments using only MEH-PPV, PSMA, or NIR775 and TEM confirmed that all three components were required to give PDs as shown in Fig. $\left.\mathrm{S}^{+}\right)$. When the $\mathrm{pH}$ of the PD dispersion was decreased to 3.8 the dispersion was destabilised and aggregates with sizes of 70 to $100 \mathrm{~nm}$ formed (see Fig. S1b, ESI $)$ ). The $\mathrm{pH}$-triggered flocculation was limited and did not result in further diffusion-limited aggregation. DLS data showed that decreasing the PD dispersion $\mathrm{pH}$ to 4.0 and below, resulted in an increase in the z-average diameter $\left(d_{z}\right)$ from 65 to $75 \mathrm{~nm}$ (see Fig. S3a, ESIt). Simultaneously, the zeta potential of the PDs decreased from $-50 \mathrm{mV}$ to $-32 \mathrm{mV}$ under these conditions (see Fig. S3b, ESI + ). Zeta potentials between 0 and $\pm 30 \mathrm{mV}$ are associated with colloidal instability ${ }^{22}$ and hence our PD dispersions were deliberately brought to the boundary of this instability region using $\mathrm{pH}$ variation and then PEA-MAA-BDDA shells grown.

Fig. 1a shows a representative scanning transmission electron microscopy (STEM) image obtained for the CSS particles. The yellow arrows highlight PDs that can be seen in the core and the outer shell. As will be discussed below, the CSS particles had a "bowl-like" morphology when dried. The low electron density inner shell is taken to be PEAA-MAABDDA. The image also shows other particles which had a similar, remarkable, CSS morphology. Additional images were obtained using dark field STEM which show the CSS morphology (Fig. S4, ESIt). We conducted an extensive investigation using conventional TEM and repeated CSS preparations. In each case the CSS morphology was apparent (see Fig. S5, ESIt). The average CSS diameter was $84 \pm 22 \mathrm{~nm}$, as obtained by manually measuring 100 particles. The differences in TEM contrast are due to differences in electron scattering. The darker domains near the particle centres in Fig. $1 \mathrm{a}$ are due to the more electron rich MEH-PPV PD-based core and the lighter regions are the inner PEA-MAA-BDDA shell. PDs can also be seen in the outer shell. For comparison, a control
PEA-MAA-BDDA dispersion was prepared without added PDs. $A$ representative TEM image obtained for that system showed low contrast featureless particles (see Fig. S6, ESIt).

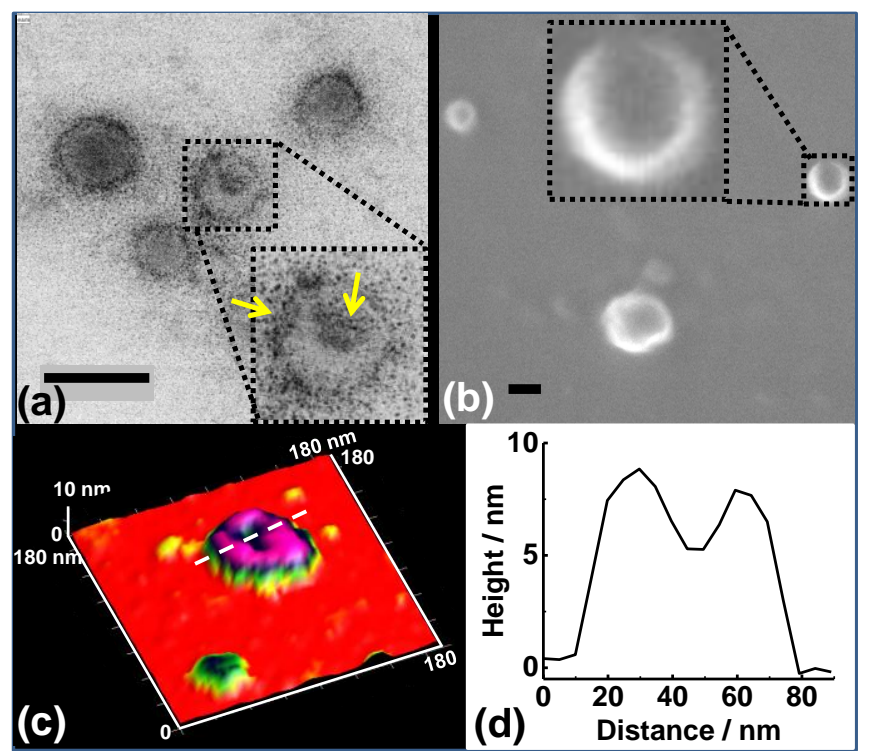

Figure 1. (a) Bright field STEM image of CSS particles. The arrows highlight the PD-rich outer shell and core. (b) SEM image measured of the CSS particles. (c) 3D AFM Peak Force Tapping mode image for CSS particles in air. (d) AFM height profile of CSS particle highlighted in (c). The scale bars represent $100 \mathrm{~nm}$.

SEM images were obtained to gain further insight into the morphology of the CSS particles. A "bowl-like" morphology was apparent (see Fig. $1 \mathrm{~b}$ and Fig. S7, ESI+). This morphology is attributed to dehydration during drying. It is stressed that no evidence of electron beam damage was detected during our SEM and TEM measurements. AFM was also employed to study the CSS particle morphology (see Fig. 1c and 1d) A representative lower resolution AFM image is shown in Fig. S8 $(E S I+)$. There were numerous particles with a shallow core region and a raised periphery. These data confirm the bowllike morphology for the deposited CSS particles in air. We propose that the PD-rich cores were relatively hydrated and de-swelled when dried. The height profile data showed that the diameter-to-height ratios were about 10 (see Fig. 1d). This result suggests that the PEA-MAA-BDDA shell had deformed and flowed during drying on the substrate. Flow and deformation for PEA particles when deposited is possible ${ }^{23}$ because the glass transition temperature of PEA is $-15^{\circ} \mathrm{C}^{8}$.

It is stressed that if the $\mathrm{pH}$ was not decreased from 5.5 to 3.8 prior to shell growth then the CSS particle morphology shown in Fig. 1a could not be prepared. We attribute the CSS morphology to the PD destabilisation depicted in Scheme S1 (ESIt). The weight fraction of MEH-PPV in the CSS particles was $\sim 40 \mathrm{wt} . \%$ on a dry weight basis by comparing the UV-visible spectrum measured for the CSS particles (Fig. 3a) to a PD calibration graph (see Fig. S9, ESIt). The method is in the ESIt.

Variable pH DLS data were measured and show that the CSS particles were slightly $\mathrm{pH}$-responsive with a $d_{z}$ of $110 \mathrm{~nm}$ at $\mathrm{pH} 5.0$ which increased by $10 \mathrm{~nm}$ for $\mathrm{pH}$ values greater than or equal to 6.0 (see Fig. S10a, ESIt). This $d_{z}$ increase corresponded to the region of maximum zeta potential (see Fig. S10b, ESI + ). The pH-response of the CSS particles is due to 
the MAA included in the inner shell. A secondary contribution to the zeta potential can be expected from the $\mathrm{COOH}$ groups of PSMA adsorbed to the PDs.

Dispersion stability is a very important property for applications of PDs involving imaging in vivo. The dispersion stability of the CSS dispersions in aqueous $\mathrm{NaCl}$ solutions was therefore investigated and compared to that for the parent PD dispersion (see Figure 2a). The dispersion pH was 5.5 except for the PBS solution which had a $\mathrm{pH}$ of 7.4. The CSS dispersions were colloidally stable by visual inspection over the whole range of $\mathrm{NaCl}$ concentrations up to $0.20 \mathrm{M}$ as well as for 0.15 M PBS solution (see Fig. 2a). In contrast, aggregation was visually evident for the parent $P D$ dispersions in the presence of 0.10 and $0.20 \mathrm{M} \mathrm{NaCl}$ (see arrow) or PBS. Aggregation resulted in decreased turbidity for these dispersions due to sedimentation. A DLS study detected aggregation when the $\mathrm{NaCl}$ concentration was only $0.05 \mathrm{M}$ (see Fig. 2b). Because DLS is more sensitive to aggregation we conclude that the onset of PD aggregation occurred at $0.05 \mathrm{M} \mathrm{NaCl}$. In contrast, the $d_{z}$ values of the CSS particles remained constant. These data strongly suggest that inclusion of a PEA-MAA-BDDA shell improves PD stability. The CSS dispersions had excellent stability at electrolyte concentrations of up to $0.20 \mathrm{M}$ which is higher than physiological ionic strength which usually requires PDs with bespoke polymer stabilisers. ${ }^{9,24,25}$
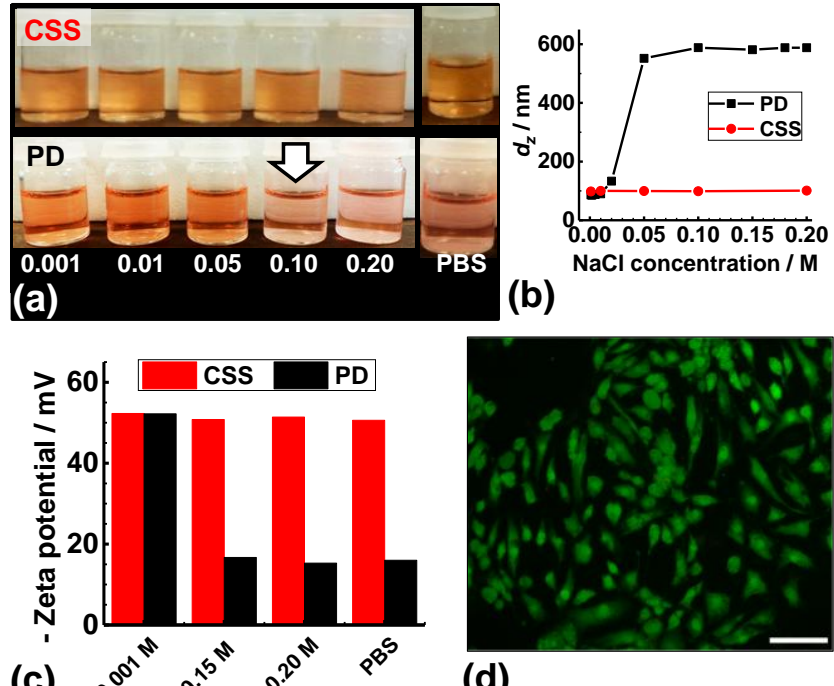

(d)

Figure 2. Dispersion images (a) and the variation of $d_{z}$ (b) with $\mathrm{NaCl}$ concentration (in M). The concentrations of the CSS and PD dispersions from (a) were $1.2 \mu \mathrm{g} / \mathrm{mL}$ and 3.0 $\mu \mathrm{g} / \mathrm{mL}$, respectively. (c) Zeta potentials of CSS and PD particles. (d) Live / dead image of NP cells in contact with $1.2 \mu \mathrm{g} / \mathrm{mL}$ CSS particles for 8 days. Live cells appear green, and dead cells appear red. The scale bar is $100 \mu \mathrm{m}$.

The cause of the superior dispersion stability of the CSS particles was probed by measuring their zeta potentials (see Fig. 2c). The zeta potentials remained large for the CSS dispersions (at -51 to $-53 \mathrm{mV}$ ), whereas those for the PD dispersion rapidly decreased in magnitude to $\sim-15 \mathrm{mV}$ at a $\mathrm{NaCl}$ concentration of $0.15 \mathrm{M}$ or in PBS. These results strongly suggest that the CSS dispersions provided stronger electrostatic repulsion at high electrolyte concentrations (which encompass physiological conditions). This trend suggests that there is potential to use the new CSS particles in vivo. Cell challenge data obtained using live dead assays show that CSS particles were not cytotoxic to human nucleus pulposus (NP) cells for up to 8 days (Fig. $2 d$ and Fig. S11, ESIt).

The optical properties of the CSS dispersions were studied using UV-visible and photoluminescence (PL) spectroscopy. The UV-visible spectra for the CSS and PD dispersions showed absorption bands assigned to the MEH-PPV and NIR775 components at $480 \mathrm{~nm}$ and $775 \mathrm{~nm}$, respectively. (see Fig. 3a). Interestingly, the incorporation of the PDs within the CSS particles caused an $18 \mathrm{~nm}$ blue-shift and an $8.0 \mathrm{~nm}$ red-shift of the MEH-PPV and NIR bands, respectively, when compared the pure PDs. A likely explanation for the blue-shift is a decrease in aggregation of MEH-PPV in the CSS particles. The NIR band red-shift may be due to a refractive index change ${ }^{26}$.

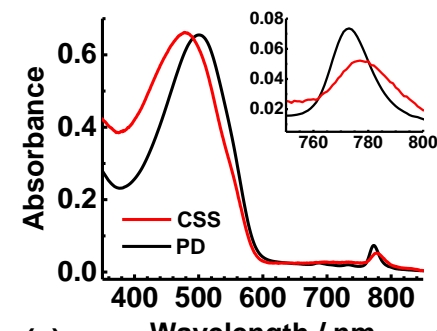
(a)
Wavelength / nm

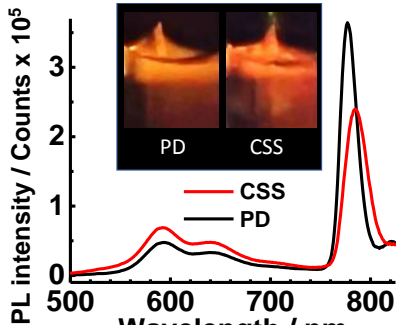

(b)

Wavelength / nm

Figure 3. (a) and (b) show UV-visible and PL spectra, respectively, for CSS $(6.6 \mu \mathrm{g} / \mathrm{mL}$ ) and PDs $(3.0 \mu \mathrm{g} / \mathrm{mL})$ dispersions in PBS buffer at $\mathrm{pH}$ 7.4. The images shown in the inset were obtained using $\lambda_{e x}=470 \mathrm{~nm}$ and a $495 \mathrm{~nm}$ filter.

PL spectra were also measured for the CSS and pure PD dispersions at $\mathrm{pH} 7.4$ (see Figure $3 \mathrm{~b}$ ). (The PL spectra measured for both systems were not affected by $\mathrm{pH}$ in the range 4.0 to 8.0 as shown in Fig. $\mathrm{S} 12+$ ). There was also a slight red-shift (of $6 \mathrm{~nm}$ ) in the NIR peak, when comparing the CSS PL spectra to that of the PDs. The PL intensities of the bands due to MEH-PPV (575 nm) and NIR775 $(775 \mathrm{~nm})$ were slightly higher and lower, respectively, for the CSS particles compared to the pure PDs. We attribute the PL increase to less emission self-quenching by MEH-PPV within the CSS particles. EA may have partially swelled MEH-PPV, resulting in reduced $\pi$ stacking. This proposal is supported by Fig. S13 (ESI $\left.{ }^{\dagger}\right)$, where partial solubility of MEH-PPV in EA is evident. The QY values for MEH-PPV and NIR775 were determined (see Table S1, $\mathrm{ESI}+$ ). The QY values for these components were 0.11 and 0.13 , respectively, for the CSS particles. There was a significant $Q Y$ increase and decrease, respectively, for these signals upon growth of the CSS particles. This result is mostly likely due to the presence of the PEA-MAA-BDDA phase in the inner shell. These values compare favourably to related QYs for MEH-PPV based PDs and PDs containing NIR775, respectively, as well as other conjugated nanoparticles (See Table S1, ESIt).

It was expected that the CSS particles could act as nonradiative energy transfer (NRET) acceptors. Hence, the ability of the CSS particles to quench the fluorescence of an added (donor) water-soluble dye (AF403) was probed (see Scheme $\mathrm{S} 2, \mathrm{ESI}+$ ). AF430 was selected as a model water-soluble donor dye because of its strong $\mathrm{PL}$ overlap with the UV-visible spectrum of MEH-PPV within the PDs (See Fig. S14, ESI†). Consequently, non-radiative energy transfer (NRET) from the dye to the MEH-PPV within the PDs was possible if the dye could approach the PDs at a distance comparable to the 
Förster distance, which is $6.5 \mathrm{~nm}^{27}$. We therefore studied the effect of CSS concentration on the PL spectra (see Fig. 4a). The $\mathrm{PL}$ spectra are dominated by AF430 with an emission maximum at $547 \mathrm{~nm}$. The signal from the NIR775 within the CSS particles can be seen at $775 \mathrm{~nm}$. There was pronounced reduction in the AF430 PL intensity at $547 \mathrm{~nm}$ with increasing CSS concentration. The variation of the PL intensity at $547 \mathrm{~nm}$ followed the Stern-Volmer equation (Fig. S15, ESIt). The increase in CSS concentration can be seen from the increase in the emission at $775 \mathrm{~nm}$ (see inset of Fig. 4a). These results strongly suggest that NRET occurred, with AF430 acting as the donor and the MEH-PPV within the CSS particles acting as the acceptor. Hence, the donor dye was able to approach within $6.5 \mathrm{~nm}$ of the MEH-PPV in the CSS particles. We attribute this to MEH-PPV in the PDs that formed the outer shell on the surface of the CSS particles (see Scheme S1, ESI+).
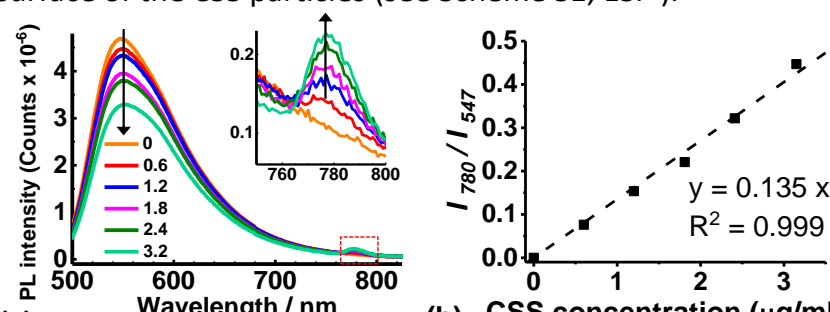

(a) Wavelength / nm

(b) CSS concentration $(\mu \mathrm{g} / \mathrm{mL})$

Figure 4. (a) PL spectra for CSS/AF430 dispersions measured using a range of CSS concentrations at $\mathrm{pH}$ 5.5. The inset shows an expanded view. The AF430 concentration was $0.0142 \mathrm{mM}$. (b) Variation of PL intensities with CSS concentration.

The change in the PL intensities due to AF430 and NIR775 are plotted as the intensity ratio in Fig. $4 \mathrm{~b}$. A linear relationship between $I_{780} / I_{547}$ and CSS concentration is apparent, as expected for a system where the CSS particles caused dye quenching. Figure S16 (ESI $)$ ) shows that the absorption of the AF430 in a dispersion with CSS particles is similar to that of AF430 in a dispersion without CSS. This suggests that the decrease in fluorescence at the AF430 peak with increasing CSS concentration observed in Fig. $4 \mathrm{a}$ is a result of quenching, and not any affect such as particle-induced dye aggregation ${ }^{28}$.

In conclusion, we have introduced a new type of CSS NIR particle. The CSS particles had a bowl-like morphology when deposited from dispersion and allowed to dehydrate. They were not cytotoxic to NP cells at a concentration where the NIR peak was clearly evident. Furthermore, the CSS particles had enhanced colloidal stability and stronger fluorescence emission when compared to the parent PD particles. Mixed CSS/AF430 dispersions also showed NRET with a water-soluble donor which suggests that the CSS particles could also be used for ratiometric detection.

\section{Conflicts of interest}

There are no conflicts to declare.

\section{Notes and references}

BRS is grateful to the EPSRC for a 5-year Established Career Research Fellowship (EP/M002020/1). The authors thank the Wellcome Trust for EM Core facility support and the referees.
1.C. F. Wu, B. Bull, C. Szymanski, K. Christensen, and J. McNeill. ACS Nano 2008, 2, 2415-2423.

2.Z. J. Chen, V. Stepanenko, V. Dehm, P. Prins, L. D. A. Siebbeles, J. Seibt, P. Marquetand, V. Engel, and F. Wurthner. Chem.-Eur. J. 2007, 13, 436449.

3. Y. Lyu, and K. Y. Pu. Adv. Sci. 2017, 4, 14.

4. H. B. Chen, J. Zhang, K. W. Chang, X. J. Men, X. F. Fang, L. B. Zhou, D. L. Li, D. Y. Gao, S. Y. Yin, X. J. Zhang, Z. Yuan, and C. F. Wu. Biomaterials 2017, 144, 42-52.

5. K. Li, and B. Liu. J. Mater. Chem. 2012, 22, 1257-1264.

6. J. G. J. L. Lebouille, R. Stepanyan, J. J. M. Slot, M. A. Cohen Stuart, and R. Tuinier. Colloids Surf., A 2014, 460, 225-235.

7. K. Landfester, R. Montenegro, U. Scherf, R. Guntner, U. Asawapirom, S. Patil, D. Neher, and T. Kietzke. Adv. Mater. 2002, 14, 651 - 655.

8.X. He, J. Wu, G. Huang, and X. Wang. J. Macromol. Sci., Part B: Phys. 2010, 50, 188-200.

9.L. Xiong, F. Cao, X. Cao, Y. Guo, Y. Zhang., and X. Cai. Bioconjugate Chem. 2015, 26, 817-821.

10. F. Y. Y. Jin, M. Zeigler, C. Wu, and D. T. Chiu. ACS Nano 2011, 5, 14681475.

11. M. B. Zeigler, W. Sun, Y. Rong, and D. T. Chiu. J. Am. Chem. Soc. 2013, 135, 11453-11456.

12. N. Anwar, A. Rix, W. Lederle, and A. J. C. Kuehne. Chem. Commun. 2015, 51, 9358-9361.

13. T. Piok, S. Gamerith, C. Gadermaier, H. Plank, F. P. Wenzl, S. Patil, R. Montenegro, T. Kietzke, D. Neher, U. Scherf, K. Landfester, and E. J. W. List. Adv. Mater. 2003, 15, 800-804.

14. K. J. McHugh, L. Jing, A. M. Behrens, S. Jayawardena, W. Tang, M. Gao, R. Langer, and A. Jaklenec. Adv. Mater. 2018, 30, 1706356.

15. C. Yang, X. Wang, S. Huang, and M. Wang. Adv. Funct. Mater. 2018, 28, 1705226.

16. T. Nguyen, V. Doan, and B. J. Schwartz. J. Chem. Phys. 1999, 110, 4068-4078.

17. S. Kim, C-K. Lim, J. Na, Y-D. Lee, K. Kim, K. Choi, J. F. Leary and I. C. Kwon. Chem. Commun. 2010, 46, 1617-1619.

18. C. Dai, D. Yang, X. Fu, Q. Chen, C. Zhu, Y. Cheng, and L. Wang. Polym. Chem. 2015, 6, 5070-5076.

19. R. Han, H. Yi, J. Shi, Z. Liu, H. Wang, Y. Hou, and Y. Wang. Phys. Chem. Chem. Phys. 2016, 18, 25497-25503.

20. C. F. Wu, Y. Jin, T. Schneider, D. R. Burnham, P. B. Smith, and D. I. T. Chiu. Angew. Chem., Int. Ed. 2010, 49, 9436-9440.

21. P. A. Lovell, and M. S. El-Aasser (1997) Emulsion Polymerization and Emulsion Polymers, Wiley.

22. ASTM Standard D4187-82, Am. Soc. Test. Mater. 1985.

23. S. Sugihara, M. Sudo, K. Hirogaki, S. Irie, and Y. Maeda. Macromolecules 2018, 51, 1260-1271.

24. H. Zhu, Y. Fang, X. Zhen, N. Wei, Y. Gao, K. Q. Luo, C. Xu, H. Duan, D. Ding, P. Chen, and K. Pu. Chem. Sci. 2016, 7, 5118-5125.

25. C. Yang, H. Liu, Y. Zhang, Z. Xu, X. Wang, B. Cao, and M. Wang. Biomacromolecules 2016, 17, 1673-1683.

26. W.-F. Xie. Commun. Theor. Phys 2015, 63, 635-640.

27. I. D. Johnson (2010) The Molecular Probes Handbook: A Guide to Fluorescent Probes and Labeling Technologies, 11th Edition, Life Technologies Corporation.

28. Y. Chen, L. Chen, H. Bai and L. Li. J.Mater.Chem.A 2013, 1, 19922001. 